\title{
Characterization of the Extracellular Polymeric Substances (EPS) of Virgibacillus strains capable of mediating the formation of high $\mathrm{Mg}$-calcite and protodolomite
}

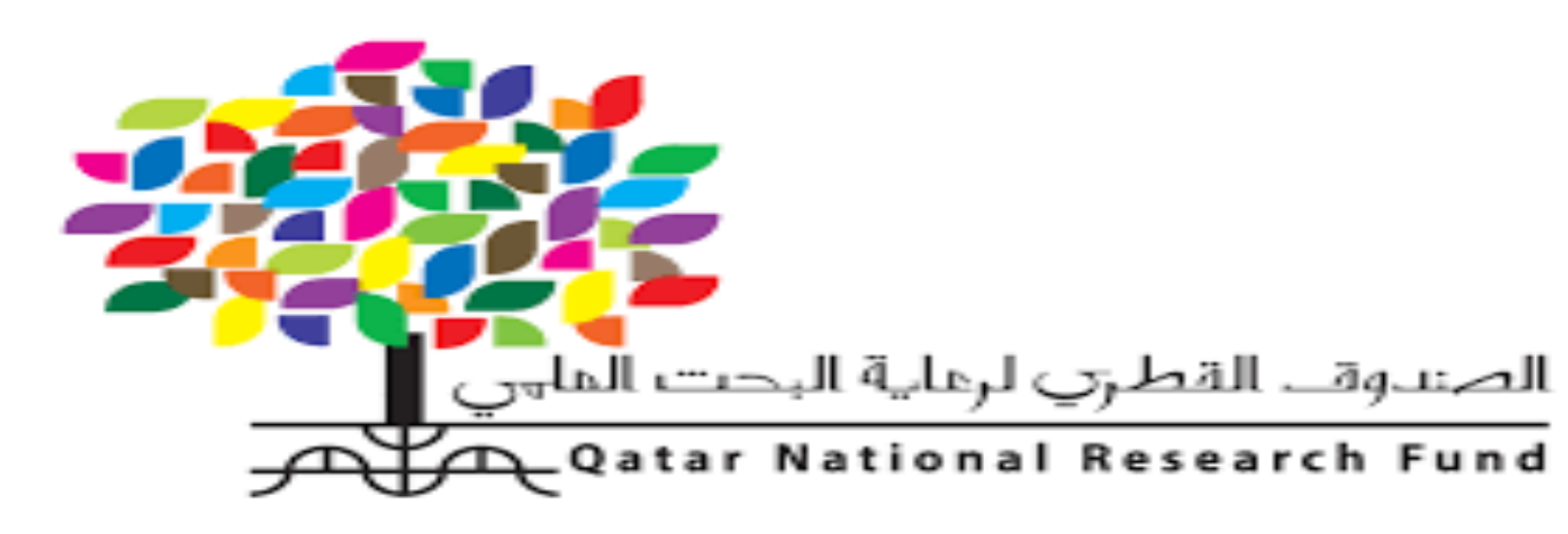

Zulfa Ali Al Disi ${ }^{1}$, Nabil Zouari ${ }^{1}$, Samir Jaoua ${ }^{1}$, Hamad Al Saad Al-Kuwari ${ }^{1}$, Maria Dittrich ${ }^{2}$ and Tomaso R.R. Bontognali, ${ }^{1,3}$

${ }^{1}$ Qatar University, Doha, Qatar, ${ }^{2}$ University of Toronto, Toronto, Canada, ${ }^{3}$ Space Exploration Institute (SPACE-X), Neuchatel Switzerland

Faculty and PostDoc,

Energy, Environment \& Resource Sustainability

(Published in Marine Chemistry - Volume 216, 2019, 103693)

\section{Abstract}

The origin of dolomite -a common carbonate mineral- is the subject of an ongoing debate. It has been proposed that extracellular polymeric substances (EPS) excreted by microbes contain specific organic molecules that facilitate the incorporation of magnesium in the carbonate minerals. We characterized the EPS produced under different conditions by measuring tota carbohydrate (TCHO), total protein (TP) content and by (FTIR) analysis. We report the formation of $\mathrm{Mg}$-carbonates with a mol\% $\mathrm{Mg}$ higher than $41 \%$ exclusively in association with EPS rich in carbohydrates (TCHO > than 75\% of the total EPS mass). Moreover, FTIR analysis of these EPS revealed the presence of protein secondary structures (e.g., $\beta$-sheets) known to favor mineral nucleation. These results suggest that some organic molecules with specific functional groups (e.g., carboxyl and hydroxyl groups) may be of key importance for overcoming the kinetic barriers that else prevent the incorporation of $\mathrm{Mg}$ into carbonate minerals, a crucial step for the formation of dolomite in natural environments.

\section{Introduction}

Dolomite is an important Mg-carbonate mineral characterizing many oil and gas reservoirs. However, the origin of dolomite and the mode of its formation remain poorly constrained. The microbial model for dolomite formation is one of the various proposed hypothesis/solutions to solve the dolomite problem. The activities of numerous microorganisms including bacteria can overcome the kinetic energy barrier required for dolomite formation. The exact mechanism(s) of biomineralization are still controversial. EPS are mainly composed of polysaccharides and proteins (Decho \& Gutierrez, 2017). In the evaporitic environments in Qatar Sabkhas, a high diversity of the bacterium Virgibacillus was evidenced in association with diversity of minerals (Al Disi et al., 2017). it is proposed that high temperature and subsequent increase in salinity and supersaturation caused by the strong evaporation may promote an ecological stress that stimulates the extensive synthesis of EPS by microorganisms (Bontognali et al., 2010). EPS of three bacterial strains previously isolated form Dohat Faishakh in Qatar were used for studying the EPS production. Different ranges of temperature and salinity were applied to modulate the EPS synthesis using an appropriate $\mathrm{Mg}^{+2}$ : $\mathrm{Ca}^{+2}$ ratio of 6 . Two mineral forming Virgibacillus strains (DF112 and DF2141) were selected to exhibit several differences in their mineral forming profiles. One non-mineral forming Bacillus licheniformis strain (DF141) was selected as producer of EPS not appropriate for mineral formation.

\section{Methods}

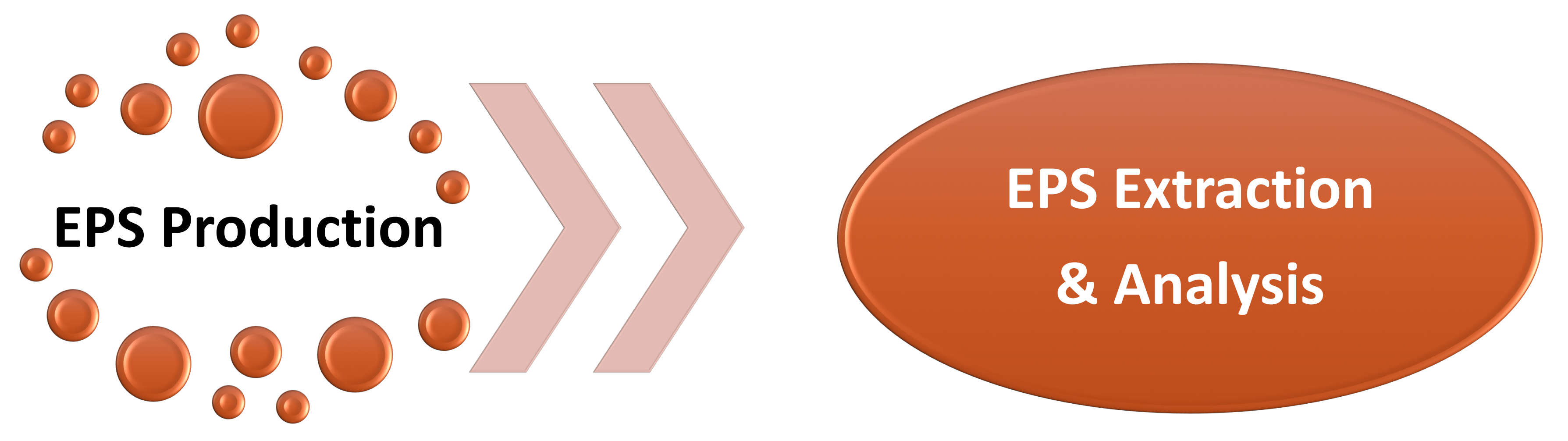

- Estimation of Total carbohydrates and protein

- Fourier Transform Infrared Spectroscopy (FTIR)

- XRD analysis

- Statistical Analysis

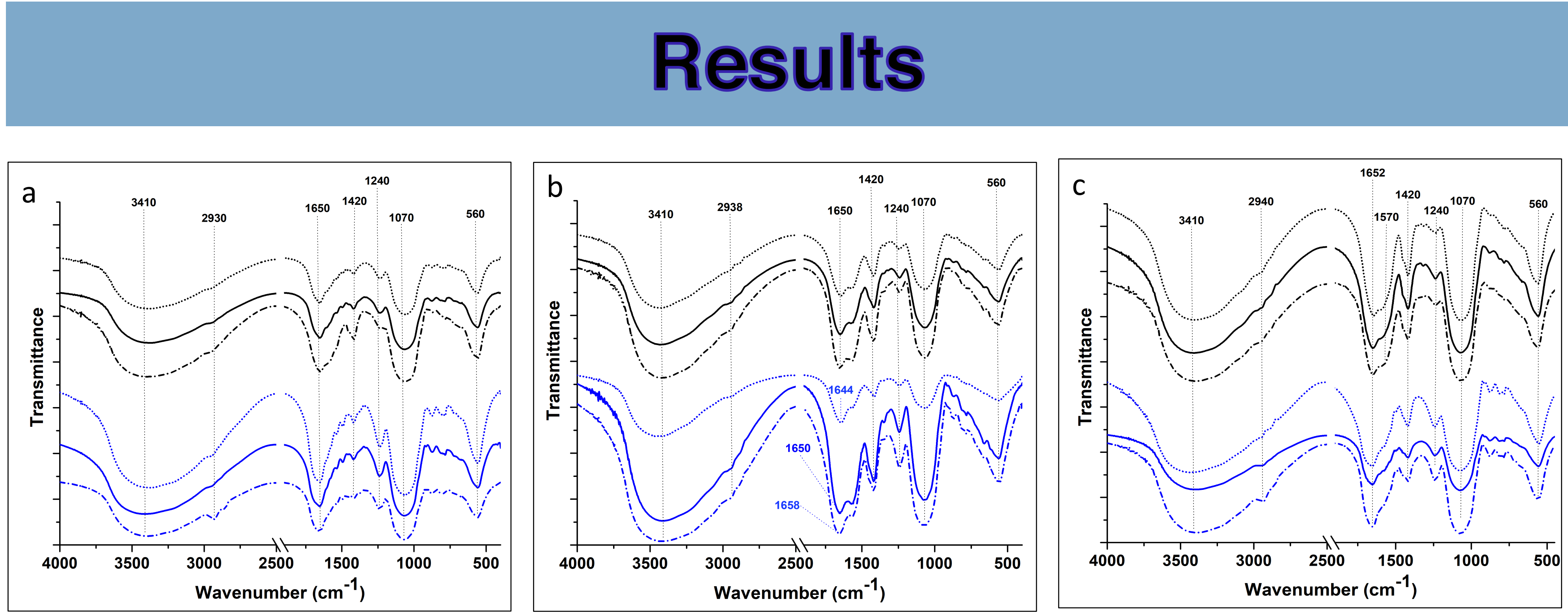

Figure 3: Representative FTIR spectra of the EPS Produced by mineral forming (blue lines) and non-minera forming strains (black lines) at incubation temperature of a) $20{ }^{\circ} \mathrm{C}$, b) $30{ }^{\circ} \mathrm{C}$ and c) $40{ }^{\circ} \mathrm{C}$ and salinity levels of $3.5 \% \ldots, 7.5 \%$ _ and $10 \%$......
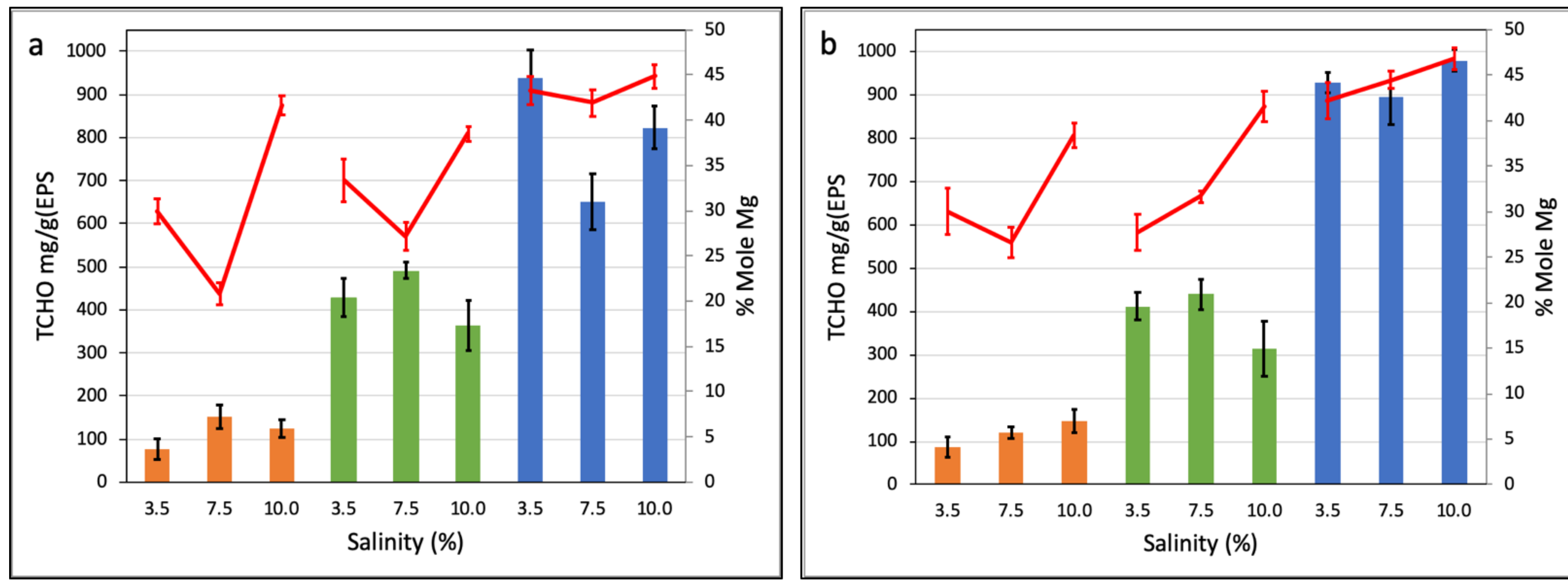

Figure 4 : Illustration of Total Carbohydrate content in the EPS produced by mineral forming strains a) DF112, b) DF2141 at different salinities $(3.5 \%, 7.5 \%$ and $10 \%)$ and incubation temperatures of $20{ }^{\circ} \mathrm{C}, \quad 30{ }^{\circ} \mathrm{C}$ and $\quad 40$ $C$ (bars). The red lines represent the \% mole $\mathrm{Mg}( \pm$ standard deviation) of the minerals formed at similar C (bars). The
conditions.

\section{Conclusion}

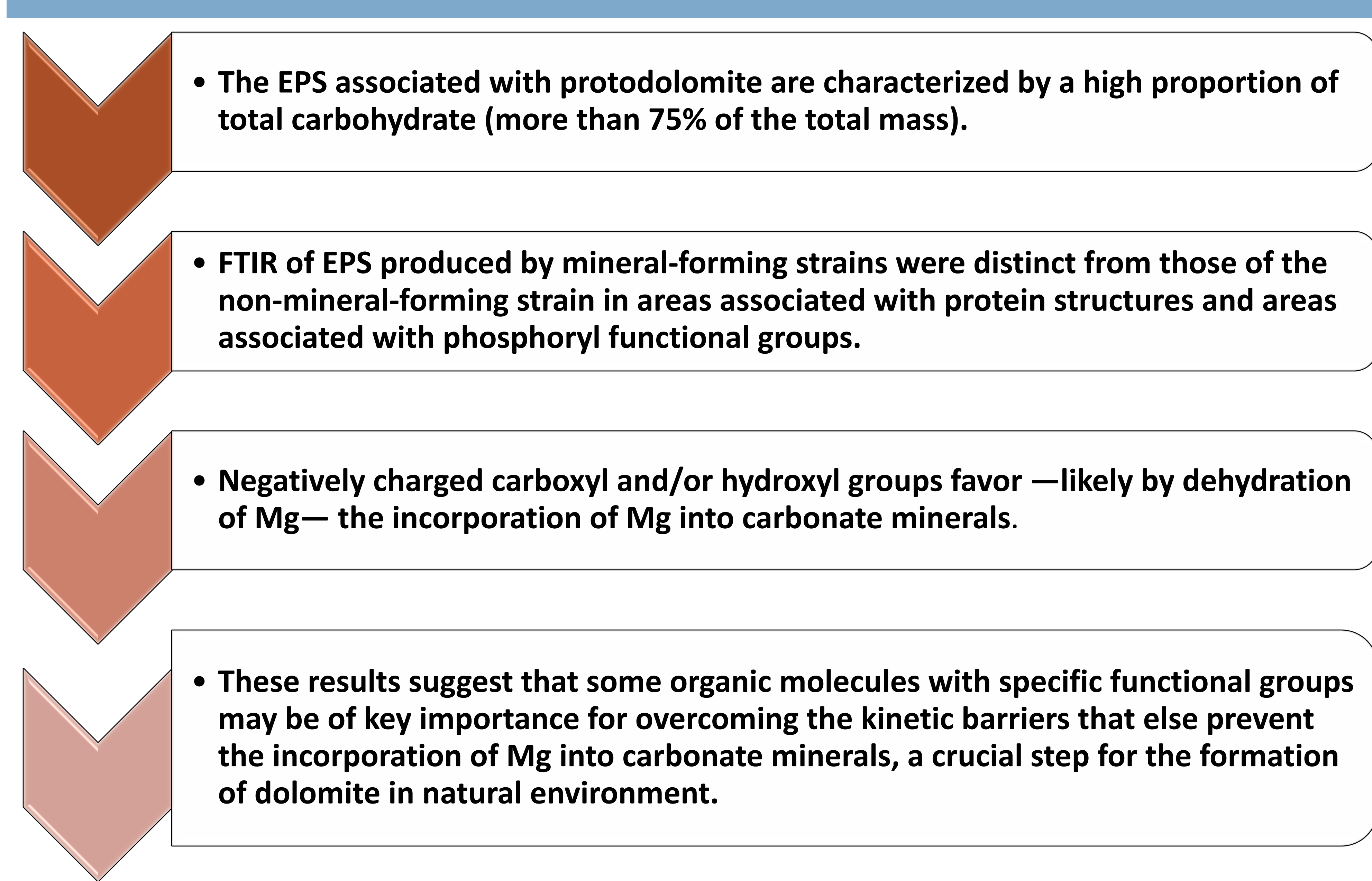

\section{References}

Al Disi, Z. A. et al., 2019. Characterization of the Extracellular Polymeric Substances (EPS) of Virgibacillus strains capable of mediating the formation of high Mg-calcite and protodolomite. Marine Chemistry

Al Disi, Z. A. et al., 2017. Evidence of a Role for Aerobic Bacteria in High Magnesium Carbonate Formation in the Evaporitic Environment of Dohat Faishakh Sabkha in Qatar. Frontiers in Environmental Science, Volume 5.

Arvidson, R. S. \& Mackenzie, F. T., 1999. The dolomite problem; control of precipitation kinetics by temperature and saturation state. Am. J. Sci, Volume 1, pp. 257-288.

Bontognali et al., 2014. Microbially influenced formation of Mg-calcite and Ca-dolomite in the presence of Exopolymeric substances produced by sulphate-reducing bacteria. Terra Nova, Volume 26, pp. 72-77.

Braissant O. et al., 2003. Bacterially Induced Mineralization Of Calcium Carbonate In Terrestrial Environments: The Role Of Exopolysaccharides And Amino Acids. J. Sediment. Res., 73(3), p. 485-490.

Decho, A. W. \& Gutierrez, T., 2017. Microbial Extracellular Polymeric Substances (EPSs) in Ocean Systems. Front Microbiol. 2017, 8(922), p. doi: [10.3389/fmicb.2017.00922].

Flemming et al., 2007. The EPS Matrix: The "House of Biofilm Cells". Journal of Bacteriology, p. 7945-7947.

Roberts, J. A. et al., 2013. Surface chemistry allows for abiotic precipitation of dolomite at low temperature. PNAS, $110(36)$, p. $14540-14545$

\section{Acknowledgments}

This publication was made possible by NPRP grant 7-443-1-083 from the Qatar National Research Fund (a member of the Qatar Foundation). The statements made herein are solely the responsibility of the authors. We would like to thank Dr. Khaled Al Saad, Head of Chemistry Department for his very kind support with the FTIR analysis, and for Dr. Peter Kazak and Mr. Abdullah Alashraf from the Center for Advanced Materials (CAM-QU) for their great help with the XRD analysis. 